\title{
Kodlama Eğitiminde İşbirlikli Öğrenme Yaklaşımı: Eşli Kodlama ${ }^{1}$
}

\author{
DOI: $10.26466 /$ opus. 680327
}

\author{
Şule Betül Tosuntaș* - Emrah Emirtekin** - Kağan Kırcaburun *** \\ * Dr. Öğr. Üyesi, Bursa Uludağ Üniversitesi, Eğitim Fakültesi, Bursa/Türkiye \\ E-Posta: sbtosuntas@uludag.edu.tr \\ ORCID: 0000-0002-0731-6505 \\ ** Uzman, Yaşar Üniversitesi, Açık ve Uzaktan Öğrenme Merkezi, İzmir/Türkiye \\ E-Posta: emrah.emirtekin@yasar.edu.tr \\ ORCID: 0000-0002-3970-4406 \\ ***Arş. Gör., Düzce Üniversitesi, Eğitim Fakültesi, Düzce/Türkiye \\ E-Posta kircaburunkagan@gmail.com \\ ORCID: $\underline{0000-0002-8678-9078}$
}

\section{$\ddot{O} z$}

Eşli kodlama, işbirlikli öğrenme temelinde kodlama eğitiminde yaygın olarak kullanılan yaklaşımlardan biridir. Kuramsal olarak eşli kodlamanın birçok avantajı olduğu bilinmektedir. Bu araştırmanın amacı ortaokul öğrencilerinin işbirlikli öğrenme ve kodlamaya yönelik tutumlarının ve eşli kodlama uygulamalarına yönelik görüşlerinin incelenmesidir. Araştırmada sırasıyla nicel ve nitel verilerin toplandığ açıklayıcı sıralı desen tercih edilmiştir. Katılımcılar, ölçüt örnekleme yoluyla belirlenmiş 220 ortaokul öğrencisidir. Öğrencilerin işbirlikli ögrenmeye yönelik tutumların belirlemek amacıyla Şahin, Arseven, Ökmen, Eriş ve Ill̆gan (2017) tarafından geliştirilen İşbirlikli Öğrenme Ölçeği kullanılmıştır. Kodlamaya yönelik tutumları ise araştırma kapsamında geliştirilen Kodlamaya Yönelik Tutum Ölçeği aractlığıyla toplanmıştır. Araştırmanın nitel verileri 6 sorudan oluşan yarı yapılandırılmış bir görüşme formu kullanılarak, odak grup görüşmeleri aracıllğıyla toplanmıştır. Araştırma sonucunda öğrencilerin işbirlikli öğrenme ve kodlamaya yönelik tutumlarının olumlu olduğu belirlenmiştir. Cinsiyet açısından işbirlikli öğrenmeye yönelik tutum puanları farklılaşmamıştır. Kodlamaya yönelik tutum puanları ise erkek öğrencilerin lehine anlamlı şekilde farklılaşmıştır. Kodlamaya yönelik tutumlarn ile işbirlikli öğgrenme yönelik tutumları arasında pozitif yönlü korelasyon olduğu tespit edilmiştir. Bu doğrultuda eşli kodlama uygulamasına yönelik görüşlerde işbirlikli öğrenmenin olumlu etkileri vurgulanmıştır. Sonuç olarak öğrencilerin hem kodlama eğitimine hem işbirlikli öğrenmeye yönelik olumlu tutumlarından yola çıkılarak, kodlama eğitiminde işbirlikli öğrenme yaklaşımının bir örneği olan eşli kodlama, teknik altyapı yetersizliği dezavantajın avantaja çevirebilme açısından önemli bir firsat ve pedagojik bir altyapı sunmaktadır.

Anahtar Kelimeler: işbirlikli öğrenme, kodlama eğitimi, eşli kodlama

\footnotetext{
${ }^{1}$ Bu çalışma Bursa Uludağ Üniversitesi Bilimsel Araştırma Projeleri Birimi tarafından ÖAP(E)-2018/12 koduyla desteklenmektedir. Çalışma 19-22 Haziran 2019 tarihlerinde VIth International Eurasian Research Congress ve 16-16 Eylül 2019 tarihlerinde International Symposium on New Issues in Teacher Education'da sunulan sözlü bildirilerin genişletilmiş halidir.
} 


\title{
Collaborative Learning Approach in Coding Education: Pair Programming
}

\begin{abstract}
Pair programming is one of the approaches that reflect cooperative learning on coding education. Theoretically, pair programming is known to have many advantages. The aim of this study is to examine the attitudes of secondary school students towards cooperative learning and coding and their views on pair programming practices. Explanatory sequential pattern, in which quantitative and qualitative data were collected consecutive, was preferred in the study. Participants are 220 secondary school students determined by criterion sampling. Cooperative Learning Scale developed by Şahin, Arseven, Ökmen, Eriş, and İl̆gan (2017) was used to determine the attitudes of students towards cooperative learning. Attitudes towards coding were collected using the Attitude towards Coding Scale developed within the scope of the research. The qualitative data of the research was collected through focus group interviews using a semi-structured interview form consisting of 6 questions. As a result of the research, it was determined that students' attitudes towards cooperative learning and coding were positive. There is no significant difference between gender in terms of attitudes towards cooperative learning. However, there is a significant difference between gender in terms of attitudes towards coding. A positive correlation was determined between the attitude towards coding and cooperative learning. Accordingly, the positive effects of cooperative learning were emphasized in the views on the application of pair programming. Consequently, based on their positive attitudes towards both coding education and cooperative learning, pair programming provides an important opportunity and pedagogical infrastructure in terms of turning the technical infrastructure disadvantage into an advantage.
\end{abstract}

Keywords: cooperative learning, coding education, pair programming 


\section{Giriş}

Teknolojinin durmaksızın gelişimi nedeniyle eğitimde yapılan en önemli reformlar teknoloji entegrasyonunu temel almaktadır. Dünyada birçok ülke çeşitli teknolojileri eğitim-öğretim sürecinde erişilebilir hale getirmektedir. $\mathrm{Bu}$ teknolojilerin eğitim-öğretim sürecine dâhil olmasıyla teknoloji entegrasyonu alanında yapılan araştırmalarda büyük hız kazanmıştır. Çeşitli teknolojilerin öğretimde kullanımının etkilerini inceleyen birçok araştırmada teknolojinin uygun pedagojik yöntemler ile birlikte kullanıldığında öğrenmeyi ve başarıyı olumlu yönde etkilediği sonuçlarına ulaşılmıştır (Albaaly ve Higgins, 2012; Malik ve Shanwal, 2015).

21. yüzyıl öğrencilerinden beklenilen araştırma ve bilgi edinme becerileri, yaratıclık, yenilik ve kariyer becerileri, kişisel beceriler ve teknoloji becerilerine sahip olmalarıdır (Giordano ve Maiorana, 2014). Medya okuryazarlığı, bilgi okuryazarlığı ve teknoloji okuryazarlı̆g gibi ihtiyaçların eklenmesiyle öğrencilerin teknoloji aktif şekilde kullanması ve yenilikleri takip etmesi gerekmektedir. Tüm bu becerilerin ve ihtiyaçların karşılanmasında kodlama/programlama eğitiminin önemli olduğu vurgulanmaktadır (Günüç, Odabaşı ve Kuzu, 2013). Kodlama eğitimi; kodlama bilgi ve becerisi kazandırmasının yanı sıra; bireylerin üst düzey düșünme becerilerini kullanmalarını gerektiren, sistematik düşünebilmeyi, problemler karşısında farklı yönlerden bakabilmeyi ve çözümler üretebilmeyi, sebep-sonuç, ilişkisi kurabilmeyi ve yaratıcı düşünmeyi de beraberinde getirmektedir (Yükseltürk ve Altıok, 2015). Dünyada kodlama eğitimi, teknolojiyi yalnızca tüketim aracı olarak değil üretim aracı olarak kullanılması vurgusuyla son yıllarda önem kazanmıştır. Bireylerin bilişim teknolojilerini sürekli kullanmalarına karşın bilişim teknolojilerine katkıları oldukça azdır ve bu durum "okuyup-yazamamak" olarak ifade edilmektedir (Kafai, Resnick, ve MaLoney, 2009). Bilgiişlemsel düşünmenin temelini oluşturan işbirliği, eleştirel düşünme, algoritmik düşünme, yaratıcı düşünme ve problem çözmeyi geliştirmek amacıyla tüm dünyada ilkokul ve ortaokul programlarına eklenmektedir. Birçok ülkeye benzer şekilde kodlama eğitimi Bilişim Teknolojileri ve Yazılım dersi öğretim programına dâhil edilerek, 6. sınıftan itibaren öğrencilere öğretilmeye başlanmıştır. 
Bilişim Teknolojileri ve Yazılım dersi öğretim programı incelendiğinde özellikle yapılandırmacı yaklaşıma uygun olarak yapılandırıldığı görülmektedir. Bu yaklaşımlar ile öğrencilerin çoklu ortam materyalleri, projeler, web günceleri gibi pek çok orijinal ürün geliştirebilmeleri, hem eğitim içeriğinin zenginleşmesine katkı sağlayacak hem de yaparak ve yaşayarak öğrenmelerini sağlayacağı öngörülmektedir. Bu ders kapsamında kazandırılması hedeflenen bilgi, beceri ve değerlere ilişkin yeterlikler öğretim programında bilişim okuryazarlığı, bilişim teknolojilerini kullanarak iletişim kurma, bilgiyi yapılandırma, işbirlikli çalışma, problem çözme şeklinde belirtilmiştir (MEB, 2017). Bilişimde okuryazarlık yeterliliği, yaşam boyu öğrenme konusunda sorumluluk alma ve bilgi ve iletişim teknolojilerini güvenli bir şekilde kullanma gibi kazanımlan ifade etmektedir. Bilişim teknolojilerini kullanarak iletişim kurma yeterliliği sosyal medyayı etkili bir şekilde kullanma, ifade etmek istenilen bilgilerin hedef kitlelerin anlayacağı şekilde paylaşabilme kazanımların ifade etmektedir. Problem çözme yeterliliği programlama mantığını öğrenerek en az bir programlama aracını etkin kullanabilme kazanımı olarak ifade edilmektedir. İşbirlikli çalışma yeterliliği sanal ortamlarda ürettikleri projeleri paylaşabilme ve bilgiyi üreterek iş birliği içinde yeni projeler üretebilme kazanımlarını ifade etmektedir.

Türkiye'de 6. Sınıfta başlayan kodlama eğitimleri; ancak kodlamayı somutlaştıran görsel ortamlar ile kolaylaştırılabilecektir. Zira kodlama belirli bir programlama diline ait kullanım kuralları bilgisi olan dil yapısı, programlama kavramları ve ilkelerine ilişkin kavramsal bilgiler ve programlamaya ilişkin problem çözme gibi zihinsel becerilerle ilişkilidir (Mayer ve Bayman, 1988). Bu açıdan önemli olan kodlama mantığının öğrencilere öğretilmesidir; sonrasında öğrencilerin farklı kodlama dilleri geçişinde yalnızca yazımsal dil bilgisinin öğrenilmesi yeterli olacaktır (Arabacıoğlu, Bülbül ve Filiz, 2007). Ortaokul seviyesindeki öğrencilerin, bilgisayar programlama sürecindeki teknik karmaşa içerisinde boğulmadan programlama mantı̆̆ını kavramasının, sonraki yıllarda öğrencilerin ilgilendikleri programlama dilleri ile çalı̧̧malarını kolaylaştıracağı düşünülmektedir (Doğan ve Kert, 2016). İlkokul/ortaokul seviyesindeki öğrencilerin programlamayı öğrenmelerini destekleyecek bazı internet siteleri ve yazılımlar bulunmaktadır. Code.org, Kodu Game ve Scratch gibi görsel/blok tabanlı programlamaya imkân sağlayan siteler öğrencilerin programlama ögrenirken o programlama dilinin söz dizimi gibi 
teknik bölümlerini öğrenerek zaman kaybetmesinin önüne geçerek kodlama mantığını öğretmek için geliştirilmiştir.

Görsel, blok tabanlı ve oyun tabanlı programlama dilleri ile yapılan çalışmalar yoğunlaşmakta ve bu çalışmalar küçük yaşlarda kodlama eğitimi alan öğrencilerin eleştirel düşünme ve problem çözme becerilerinde artş, olduğu sonucuna ulaşılmıştır (Kaucic ve Asic, 2011; Kobsiripat, 2015). Geliştirilen Alice, Microsoft Small Basic, Scratch, Stagecast Creator ve Toontalk gibi programlamayı somutlaştıran ve öğrenmeyi kolaylaştıran ortamlar (Keçeci, Alan ve Kırbağ Zengin, 2016) ile kodlama eğitimi öğrencilerin okuma yazma bilgisine ihtiyaç duymadan -okul öncesi dönemde- kodlama yapabilmesini sağlamaktadır. Bu ortamlar ile kodlamaya küçük yaşlarda başlayan öğrenciler için görsel programlama dilleri ile kodlama eğitimi oldukça kolay, anlaşılır ve eğlenceli olarak görülmektedir. Bilgisayar programlama eğitimi sadece profesyonel programcılar yetiştirmeyi değil aynı zamanda, 21. yy bireylerinin yaratıc fikir geliştirme süreçlerini de desteklemeyi amaçlamaktadır (Kafai vd., 2009). Kafai (2007), öğrencilerin yaratıcı bir şekilde içerik oluşturup paylaşmalarında bilgisayar oyunu geliştirme yazılımların uygun ortamları sağladığını belirtmektedir. Bu açıdan, bilgisayar programlamayı öğrenmenin öğrencilerin kendilerini ifade etme ve iletişimi geliştirme açısından da uygun bir ortam yarattığı söylenebilir.

\section{Code.org}

Bilgisayar bilimlerini teşvik etmek amacıyla kurulan kâr amacı gütmeyen bir organizasyon olan code.org Microsoft, Facebook ve Dropbox gibi büyük platformların desteğini almaktadır (Code.org, 2018). Açık kaynak projesi olarak geliştirilen code.org; öğrencilere ve öğrenmek isteyen herkese programlamanın temel kavramlarını (döngüler, koşullar, mantıksal bağlaçlar vb.) çeşitli oyun senaryoları ile öğretmeye çalışılmaktadır. Bireyler verilen görevleri çeşitli blokları sürükle-bırak yöntemiyle tamamlamaya çalışırlar. Bu bağlamda, öğrenme ortamının blok tabanlı, görsel ve oyun tabanlı programlama yöntemi özelliklerinin hepsini aynı anda gösterdiği söylenebilir. Kodlama öğrenmeyi eğlenceli hale getirmesinin yanı sıra öğrenenlerin öğrenme sürecinde ihtiyaç duyabileceği, yol gösterici birçok etkinlik ve kaynak çevrimiçi sunulmaktadır. Bu etkinlikler ve kaynaklar 30'dan fazla dile çevrilerek dünya genelinde daha çok öğrenenin faydalanmasına olanak sağlanmıştır. Code.org 
üzerinde öğretmen ve öğrenciler için farklı hesap oluşturma seçenekleri bulunmaktadır ve öğretmenler oluşturdukları sınıflar aracılı̆̆ıyla öğrencilerinin gelişimini takip edebilmektedir. Kodlama eğitimini teşvik etmek amacıyla gerçekleştirilen küresel girişimlerden biri olan code.org her öğrencinin bilgisayar programlama/kodlamayı öğrenebilmesi adına çeşitli kampanyalar başlatmaya ve uygulamaya devam etmektedir.

\section{İşbirlikli Öğrenme ve Eşli Kodlama}

Grup çalışmalarının temelinde işbirliği kavramı bulunmaktadır. Dewey, Piaget, Vygotsky, Bruner ve Slavin' in öncülük ettiği işbirlikçi öğrenmede, bilişsel kazanımların yanı sıra duyuşsal ve sosyal kazanımlar öne çıkmaktadır. İşbirlikçi öğrenme, öğrencilerin küçük gruplarla bir problemi çözmek veya bir görevi yerine getirmek için ortak bir amaçla birlikte çalışmalarıdır. Grup üyelerinin birbirine katkısı, grup dinamiği ve grup içerisinde sorumlulukların paylaşılması önemlidir. Öğrenciler, grubun bir bütün olduğunu ve grubun başarı veya başarısızlığından bütün üyelerin sorumlu olduğunu bilmelidirler. Sonuçta elde edilen başarı gruptaki tüm üyelerin başarısıdır (Demirel, 2008; Sünbül, 2011). Öğrencilerin gruplara ayrılarak, dayanışma içinde görevleri tamamlaması, sosyal ihtiyaçlarının da karşılanacağı etkili bir yoldur (Erciyeş, 2007). Geleneksel öğrenme yönteminde pasif dinleyici olan öğrencilerin rolleri bu yöntemde tam tersi olarak değişmekte öğrenciler öğrenme sürecine aktif olarak dâhil oldukları kalıcı öğrenmeler gerçekleşmektedir. İşbirliğine dayalı öğrenmenin başarıyı yükseltme, özsaygı geliştirme, derse ve okula karşı pozitif tutum sağlama, üst düzey düşünme becerilerini geliştirmeye yardımcı olma gibi birçok katkısı vardır (Demirel, 2008).

İşbirlikli öğrenme sürecinde her bir öğrenci grup bilincini taşımalı ve sorumluluk sahibi olmalıdır. Öğrenci, kendisinin ve arkadaşlarının öğrenmesinin sorumluluğunu taşıyan, öğrenme etkinlikleri sırasında bazen öğrenci, bazen öğretici olan, araştıran, soru soran, yanit veren, kararlar alan, konuşan kısacası aktif bir role sahiptir. Bu yaklaşım öğrencilerin hem kendi bilişsel yapılarını hem de arkadaşlarının bilişsel yapılarını oluşturarak anlamlı öğrenmelerine, ayrıca sürece etkin katılım göstermelerine izin verir (Açıkgöz, 1992). Öğretmenin sorumluluğu ise grup çalışmalarının etkili olması adına rehber olmak, gruplar arası ve grup içi olası çatışmaları çözmek, işbirlikli öğ- 
renmeyi belirli kriterlere göre değerlendirmedir (Yüksel, 2017). İşbirlikli öğrenme etkinliklerinin başarıya ulaşabilmesi için (i) grup ödülü, (ii) olumlu bağlllık, (iii) yüzyüze etkileşim, (iv) bireysel değerlendirilebilirlik, (v) sosyal beceriler, (vi) grup süreçlerinin değerlendirilmesi, (vii) eşit başarı fırsatı ilkelerine uyulması gerekmektedir.

Kodlama eğitimi, bilgisayarsız etkinlikler, blok tabanlı programlama, robotik programlama ve oyun tabanlı öğrenme gibi çeşitli yaklaşımlar kullanılarak verilmektedir. İşbirlikli öğrenmenin kodlama eğitimine bir yansıması olan eşli kodlama ise bu yaklaşımlardan biridir. Çevik ve aykırı programlamanın bir uygulaması olarak mühendislik alanında yoğun olarak çalışılmakta; iş ve performans süreçlerinde kullanılmaktadır (Demir ve Seferoğlu, 2017). İşbirlikli öğrenme özellikleri ve ilkeleri göz önünde bulundurulduğunda eşli kodlama uygulamasının ne denli uygun olduğu görülmektedir.

Eşli kodlama sürecinde tek bir bilgisayarı iki öğrencinin kontrol etmesi sağlanır. Öğrencilerden biri bilgisayarın başına oturan ve kontrol eden (driver) ve diğer öğrenci ise kontrol edenin yanına oturarak yardımcı olan yönlendirici (navigator) olarak adlandırılmaktadır. Kodlama eşler tarafından beraber yapılabileceği gibi (Beck ve Andres, 2004); bireysel kodlamalara da yer verilebilmektedir (William ve Kessler, 2002). Kuramsal olarak eşli kodlamanın birçok avantajı olduğu görülmektedir.

(i) Sözelleştirme yoluyla öğrencilerin sahip oldukları örtük bilgiyi açı hale getirmektedir. Yakınsak gelişim alanı çerçevesinde bilginin transferi sağlanır (Demir ve Seferoğlu, 2017).

(ii) Bireysel kodlama eğitimi ve iş performansı ile karşılaştırıldığında eşli kodlama daha az hata yapılmasını sağlamakta ve kodlamayı eğlenceli hale getirmektedir (Cockburn ve Williams, 2000; Lui ve Chan, 2003).

(iii) Bilgisayar laboratuvarlarının yetersizliği nedeniyle iki öğrenci bir bilgisayar kullanabilmektedir.

(iv) Eşli kodlamada öğrencilerin deneyimlerine göre eş olarak belirlenmesi sayesinde, öğrenciler arasında bilgi transferi artmakta ve eksik öğrenmelerin karşılıklı tamamlanabilmesine olanak sağlanmaktadır.

Bireysel kodlama performansını etkileyen değişkenlere yönelik çok sayıda araştırma bulunmaktadır, ancak eşli kodlama daha yeni bir yaklaşım olması nedeniyle öğrencilerin eşli kodlama performansını etkileyen değişkenlerin belirlendiği çalışmalara ihtiyaç duyulmaktadır (Demir ve Seferoğlu, 
2017). Doğan ve Kert (2016) 'in çalışmasında Kodu Game Lab ortamı kullanılarak ortaokul öğrencilerinin bilgisayar oyunu geliştirmelerinin eleştirel düşünme ve algoritma başarılarına etkisi incelenmiştir. Çalışmada algoritma ve programlamanın olumlu etkisi olduğu sonucuna ulaşılmıştır. Literatürde yer alan bu ve benzeri çalışmalar bireysel kodlama performansına yönelik olup çeşitli öğrenme ortamları kullanılmıştır (Kalelioğlu, 2015, Yılmaz, 2019; Yüksel, 2017). Bu açıdan code.org ortamı kullanılarak eşli kodlama eğitimi yapılan araştırmalara ulaşılamamıştır. Dünyada yazılım alanında yetişmiş insan ihtiyacı doğrultusunda, kodlama/programlama eğitimine verilen önem giderek artmaktadır. Bu durum kodlama eğitimi yaşının okul öncesine kadar düşmesini sağlamıştır. Literatürde önemi sıklıkla vurgulanan ve yoğun şekilde araştırmaların ve uygulamaların yapıldığı kodlama eğitimi alanına; işbirlikli öğrenme yaklaşımına dayanan eşli kodlama uygulamasını kazandırmanın önemli bir katkı olacağı düşünülmektedir. Zira teknoloji destekli, işbirlikli ve etkileşimli öğrenme ortamları teknoloji entegrasyonu bağlamında ele alınan önemli çalışma alanlarından biridir. Bu anlamda bu çalışmanın literatürde sıklıkla araştırmaların yapılması önerilen birden çok alana yönelik olduğu görülmektedir. Bu bağlamda araştırmanın amacı ortaokul öğrencilerinin işbirlikli öğrenme ve kodlamaya yönelik tutumlarının ve eşli kodlama uygulamalarına yönelik görüşlerinin incelenmesidir. Bu amaçla aşağıdaki sorulara yanit aranmıştır:

1. Öğrencilerin işbirlikli öğrenmeye yönelik tutumları ne düzeydedir?

2. Öğrencilerin eşli kodlamaya yönelik tutumları ne düzeydedir?

3. Öğrencilerin işbirlikli öğrenme ve eşli kodlamaya yönelik tutumları cinsiyete göre farklılaşmakta mıdır?

4. Öğrencilerin işbirlikli öğrenme ve eşli kodlamaya yönelik tutumları ilişkili midir?

5. Öğrencilerin kodlama ve eşli kodlamaya yönelik görüşleri nasıldır?

\section{Yöntem}

Bu bölümde araştırma modeli, katılımclar, veri toplama araçları ve verilerin analizine ilişkin bilgilere yer verilmiştir. 


\section{Araştırma Modeli}

$\mathrm{Bu}$ araştırmada nicel ve nitel verilerden yola çıkılarak farklı bakış açılarının karşılaştırılabilmesi (üçgenleme); nitel ve nicel verilerin birbirini zenginleştirebilmesi (tamamlama) gerekçelerine dayanarak karma yöntem tasarımlarından açıklayıcı sıralı desen tercih edilmiştir (Creswell ve Plano Clark, 2011). Açıklayıcı sıralı desen, araştırmada sırasıyla nicel ve nitel verilerin toplandığı bir araştırma desenidir. Bu araştırmada izlenen süreç Şekil 1. de sunulmuştur.

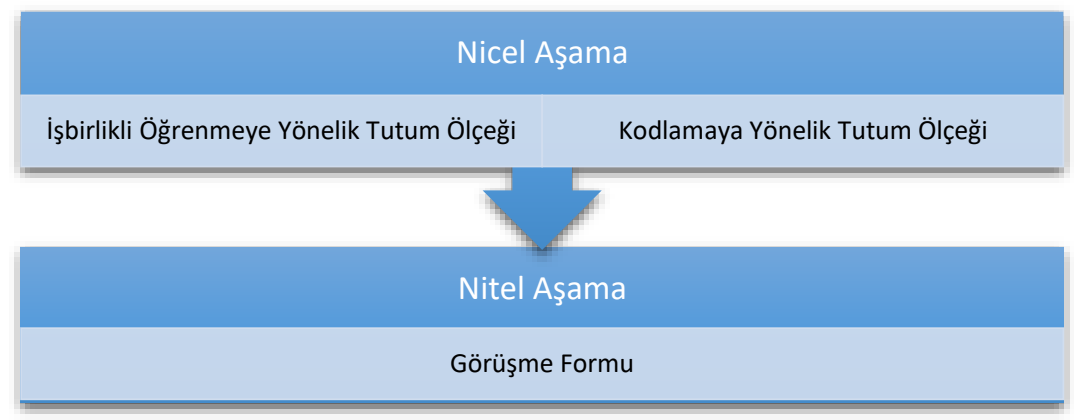

Şekil 1. Araştırma süreci

\section{Katılimcilar}

Araştırmanın katılımcıları ölçüt örnekleme yoluyla belirlenmiş, Marmara bölgesinde bir ortaokulda öğrenim görmekte olan 6. sinıf öğrencilerinden oluşmaktadır. Araştırmaya katılım ölçütü "daha önce kodlama eğitimine katılmamış ve araştırma kapsamında kodlama eğitimi almış" olmak şeklinde belirlenmiştir. Ölçüt örnekleme, bir durumun derinlemesine incelenmesi için araştırmacının belirli örnek olay türlerini belirlemek istediğinde kullanılan bir yöntemdir (Neuman, 2007). Araştırma kapsamında ölçütü sağlayan 220 öğrenci eşli kodlama uygulamalarına katılmıştır. 220 öğrencinin 115'i erkek (\%52.27), 105'i kız (\%47.73) öğrencidir. 6 farklı sınıftan gönüllü olarak toplam 62 öğrenci araştırmanin nitel boyutunu oluşturan odak grup görüşmelerine katılmıştır. 


\section{Veri Toplama Araçları}

Araştırmanın nicel verileri 2 farklı ölçek kullanılarak toplanmıştır. Öğrencilerin işbirlikli öğrenmeye yönelik tutumlarını belirlemek amacıyla Şahin, Arseven, Ökmen, Eriş ve İlğan (2017) tarafından geliştirilen İşbirlikli Öğrenme Ölçeği kullanılmıştır. İşbirlikli Öğrenme Ölçeği 28 maddeden oluşan tek faktörlü yapıda ve katılma derecesinin belirtildiği 5'li Likert tipindedir. Araştırma kapsamında ölçeğin iç tutarlılık katsayısı .96 olarak belirlenmiştir.

Literatür incelendiğinde ortaokul öğrencilerinin kodlamaya yönelik tutumun belirlenmesi amaciyla kullanılabilecek geçerli ve güvenilir bir ölçme aracına erişilememiştir. Bu bağlamda araştırma kapsamında geliştirilen Kodlamaya Yönelik Tutum Ölçeği kullanılmıştır. Öncelikle literatürde kodlama ve tutuma yönelik ölçekler incelenerek madde havuzu oluşturulmuştur. 24 maddeden oluşan bir taslak ölçek 4 alan uzmanının görüşüne sunulmuştur. Uzmanların görüşleri doğrultusunda gerekli düzeltmeler yapılmıştır. Ölçeğin madde ayırt edicilik, geçerlik ve güvenirlik analizleri yapılmıştır. Madde ayırt ediciliği için madde-toplam, madde-kalan, korelasyon analizi değerlerini belirlemek amaciyla Pearson çarpım momentler korelasyon analizi; $\% 27^{\prime}$ lik alt-üst grup madde puanlarının karşılaştırılmasında bağımsız grup ttesti kullanılmıştır. Madde analizlerinde ölçekten herhangi bir madde çıkarılmamıştır.

Ölçeğin yapı geçerliliğinin belirlenmesi için maksimum olabilirlik tekniğiyle doğrulayıc faktör analizi yapılmış ve uyum indeksleri belirlenmiştir [ $\chi 2=769.11, \mathrm{df}=249]$. Ki-karenin serbestlik derecesine oranının [ $\chi 2 / \mathrm{df}=3.08] 2-$ 5 arasında olması iyi uyumu göstermektedir (Jöreskog ve Sörbom, 2001). Tablo 1. de sunulan uyum iyiliği indeksleri ise [RMSEA=.08, AGFI=.73, $\mathrm{GFI}=.77, \mathrm{CFI}=.88, \mathrm{NFI}=.83$ ] ölçek için önerilen ölçek yapısının uygun olduğunu işaret etmektedir (Anderson ve Gerbing, 1984; Cole, 1987; Marsh, Balla ve McDonald, 1988). 
Tablo 1. Kodlamaya Yönelik Tutum Ölçeği Uyum İyiliği İndeksleri

\begin{tabular}{ll}
\hline Uyum İyiliği İndeksleri & Kat Sayı \\
\hline NFI & .83 \\
GFI & .77 \\
AGFI & .73 \\
CFI & .88 \\
RMSEA & .08 \\
Df & 249 \\
$\chi 2$ & 769.11 \\
$\chi 2 /$ df & 3.08 \\
\hline
\end{tabular}

Yapı geçerliği sonucunda Kodlamaya Yönelik Tutum Ölçeği, hiç katılmıyorum'dan (1) kesinlikle katilıyorum'a (5) uzanan beşli Likert tipinde 24 maddeden oluşmaktadır. Ölçeğin ilgi, inanç ve istek olmak üzere 3 alt boyutu bulunmaktadır.

1. İlgi: Bu alt ölçekten alınan yüksek puan kodlama eğitimine ilginin ve kodlamanın kolaylığına ilişkin görüşlerin yüksek olduğunu göstermektedir. Bu alt ölçeğe ait örnek maddeler şu şekildedir:

a) Kodlama yapmak çok karmaşıktır.

b) Kodlama yapmak ilgimi çekiyor.

2. İnanç: Bu alt ölçekten alınan yüksek puan bireyin kodlamanın performansına ve becerilerine olumlu etkisi olacağına dair görüşlerini işaret etmektedir. Bu alt ölçeğe ait örnek maddeler şu şekildedir:

a) Kodlama yapmanın geleceğim için çok faydalı olduğunu düşünüyorum.

b) Kodlamanın problem çözme becerilerimi geliştireceğini düşünüyorum.

3. İstek: Bu alt ölçekten alınan yüksek puan kodlama eğitimine ilişkin olumlu duyguları göstermektedir. Bu alt ölçeğe ait örnek maddeler şu şekildedir:

a) Kodlama yaparken kendimi iyi hissediyorum.

b) Kodlama yaparken çok eğleniyorum.

Ölçeğin güvenirlik iç tutarlılık yöntemiyle incelenmiştir. Ölçeğin alt boyutlarının Cronbach Alpha iç tutarlılık katsayıları .87 ile .95 arasında değişmektedir. Ölçeğin tamamına ait iç tutarlılık katsayısı ise .92 olarak belirlenmiştir. Tablo 2. de alt ölçeklere ilişkin madde sayıları ve iç tutarlılık katsayıları sunulmuştur. 
Tablo 2. Kodlamaya Yönelik Tutum Ölçeği Cronbach Alpha Güvenirlik Katsayıları

\begin{tabular}{lll}
\hline Alt Ölçekler & Madde Sayısı & Cronbach Alpha \\
\hline Kodlamaya Yönelik Tutum Ölçeği & 24 & .92 \\
İgi & 7 & .87 \\
İstek & 10 & .95 \\
İnanç & 7 & .92 \\
\hline$n=220$ & & \\
\hline
\end{tabular}

Araştırmanın nitel verileri 6 sorudan oluşan yarı yapılandırılmış bir görüşme formu kullanılarak, odak grup görüşmeleri aracılığıyla toplanmıştır. Görüşme formunda yer alan sorular eşli kodlama, kodlama eğitimi, işbirlikli öğrenme, takım çalışması, arkadaşlık ilişkileri, sorunlar vb. üzerinde durulmuştur.

\section{İşlem}

Araştırmada code.org platformu üzerinde yer alan eğitimler kullanılmıştır. Code.org Milli Bakanlığı tarafından Eğitim Bilişim Ağı (EBA) üzerinde öğrencilere sunulan hizmetlerden biridir. Code.org'un seçilmesinde (i) Türkçe içeriklerin uygunluğu, (ii) kazanımların öğrencilerin gelişim özelliklerine uygunluğu, (iii) MEB onaylı olması, (iv) ücretsiz olması ve (v) tablet, cep telefonu gibi birçok teknolojik altyapıya uygun olması göz önünde bulundurulmuştur. Araştırmanın teorik modeli açısından bakıldığında ise code.org eşli kodlama ve işbirlikli öğrenmeye uygun bir ortam sunmaktadır. Araştırma eşli kodlama uygulaması haftalık 2 saat olmak üzere 8 hafta sürmüştür.

Uygulama süreci sonrasında İşbirlikli Öğrenmeye Yönelik Tutum Ölçeği ve Kodlamaya Yönelik Tutum Ölçeğinden oluşan nicel veriler toplanmıştır. Nicel verilerin analizinde betimsel istatistikler, basıklık-çarpıklık değerleri, Pearson Momentler Çarpım Korelasyonu, t-testi kullanılmıştır.

Nitel veriler ise yaklaşık 15 dakika süren odak grup görüşmeleri aracılığıyla toplanmıştır. Araştırma etik kurul izniyle ses kaydına alınmıştır. Ses kayıtlarının araştırmacılar tarafından yazılı dökümü yapılmıştır. Verilerin analizinde önceden belirlenmiş araştırma soruları ve kuramsal çerçeve doğrultusunda kuramsal tematik analiz kullanılmıştır (Braun ve Clarke, 2019). Araştırmacılar tarafından ayrı ayrı kodlanan veriler, anlamlı bütünler oluşturacak şekilde temalaştırılmıştır. Betimsel analiz kapsamında katılımcıların konu ile 
ilgili dikkat çekici ifadelerine alıntılar olarak yer verilmiştir. Geçerlik ve güvenirlik sağlamak adına önlemler alınmıştır. Katılımcıların isimlerine yer verilmemiş ve araştırma sürecinde gerçekleştirilen her aşama ayrıntılı olarak açıklanmıştır.

\section{Bulgular}

$\mathrm{Bu}$ araştırmanın amacı işbirlikli öğrenme yaklaşımıyla gerçekleştirilen eşli kodlama uygulamalarına yönelik öğrencilerin görüşlerini almaktır. Araştırmanın yanıt aradığı ilk iki araştırma sorusu öğrencilerin işbirlikli öğrenme ve kodlamaya yönelik tutumlarının ne düzeyde olduğudur. Bu sorulara yönelik işbirlikli öğrenme ve kodlamaya yönelik tutum puanlarına ilişkin betimsel istatistikler Tablo 3.te sunulmuştur.

Tablo 3. Ölçeklere İlişkin Betimsel İstatistikler

\begin{tabular}{llll}
\hline & $n$ & $\boldsymbol{X}$ & SS \\
\hline İşbirlikli öğrenmeye yönelik tutum & 220 & 4.22 & .87 \\
\hline Kodlamaya yönelik tutum & 220 & 3.41 & .88 \\
İgi & 220 & 2.69 & 1.18 \\
İstek & 220 & 3.66 & 1.17 \\
İnanç & 220 & 3.77 & 1.13 \\
\hline
\end{tabular}

Tablo 4. İşbirlikli Öğrenmeye Yönelik Tutum Ölçeğinin Cinsiyete Göre T-Testi Sonuçlarn

\begin{tabular}{lllllll}
\hline & Cinsiyet & $\boldsymbol{\eta}$ & $\mathbf{X}$ & SS & $\mathbf{t}$ & $\mathbf{p}$ \\
\hline \multirow{2}{*}{ İşbirlikli öğrenmeye yönelik tutum } & Erkek & 115 & 4.20 & .83 & -.32 & .75 \\
& $\mathrm{Klz}$ & 105 & 4.24 & .67 & & \\
\hline$S D=218$ & & & & & & \\
\hline
\end{tabular}

Tablo 4. e göre öğrencilerin işbirlikli öğrenmeye yönelik tutum puanları arasında istatistiksel olarak anlamlı bir fark yoktur ( $t=-.32, p>.05)$. Bu açıdan erkek ve kız öğrencilerin işbirlikli öğrenmeye yönelik tutumlarının benzer olduğu söylenebilir. 
Tablo 5. Kodlamaya Yönelik Tutum Ölçeğinin Cinsiyete Göre T-Testi Sonuçlarn

\begin{tabular}{lllllll}
\hline & Cinsiyet & $\boldsymbol{\eta}$ & $\mathbf{X}$ & SS & $\mathbf{t}$ & $\mathbf{p}$ \\
\hline \multirow{2}{*}{ Kodlamaya yönelik tutum } & Erkek & 115 & 3.61 & .80 & \multirow{2}{*}{3.66} & $.00^{*}$ \\
& Kiz & 105 & 3.19 & .91 & & \\
\multirow{2}{*}{ Ilgi } & Erkek & 115 & 2.90 & 1.20 & 2.79 & $.00^{*}$ \\
\multirow{2}{*}{ İstek } & Kiz & 105 & 2.46 & 1.12 & & \\
& Erkek & 115 & 3.90 & 1.12 & \multirow{2}{*}{3.18} & $.00^{*}$ \\
İnanç & Kız & 105 & 3.40 & 1.17 & & \\
\hline$S D=218$ & Erkek & 115 & 3.91 & 1.09 & \multirow{2}{*}{1.99} & $.04^{*}$ \\
\hline
\end{tabular}

Tablo 5. te sunulduğu üzere kodlamaya yönelik tutum puanları arasında ise erkek öğrenciler lehine istatistiksel olarak anlamlı bir fark bulunmuştur $(\mathrm{t}=3.66$, $\mathrm{p}<.05)$. Kodlamaya yönelik tutum alt boyutlarında cinsiyete göre farklılaşma incelendiğinde ise, ilgi $(\mathrm{t}=2.79, \mathrm{p}<.05)$, istek $(\mathrm{t}=3.18, \mathrm{p}<.05)$ ve inanç $(\mathrm{t}=1.99, \mathrm{p}<.05)$ olmak üzere tüm alt boyutlarda erkek öğrencilerin lehine istatistiksel olarak anlamlı bir fark bulunmuştur. Buna göre erkek öğrencilerin kodlamaya yönelik tutumlarının genel anlamda daha olumlu olduğu söylenebilir. İşbirlikli öğrenme ve kodlamaya yönelik tutum puanları arasındaki ilişki Pearson momentler çarpım korelasyon analizi ile incelenmiştir ve sonuçları Tablo 6. da sunulmuştur.

Tablo 6. İşbirlikli Öğrenme ve Kodlamaya Yönelik Tutum Arasında Korelasyon Matrisi

\begin{tabular}{llll}
\hline \multicolumn{2}{l}{ Değişkenler } & $\mathbf{1}$ & $\mathbf{2}$ \\
\hline $1-$ & İsbirlikli Öğrenme & 1 & - \\
$2-$ & Kodlama & $.45^{*}$ & 1 \\
\hline$n=220,{ }^{*} \mathrm{p}<.05$ & & .08 \\
\hline
\end{tabular}

Tablo 6. da görüldüğgü üzere öğrencilerin işbirlikli öğrenmeye yönelik tutum puanları ile kodlamaya yönelik tutum toplam puanları arasında $(\mathrm{r}=45)$ pozitif yönlü anlamlı bir ilişki belirlenmiştir.

Öğrencilerin odak grup görüşmeleri aracılığıyla kodlama eğitimi ve eşli kodlamaya yönelik görüşleri ise kodlama eğitimi ve eşli kodlama olmak üzere iki tema altında incelenmiştir. Kodlama eğitimi teması altında öğrencilerin olumlu ve olumsuz görüsslerine yer verilmiştir. Bu tema altında tekrarlanan kodlarda Şekil 2.de sunulmuştur. 


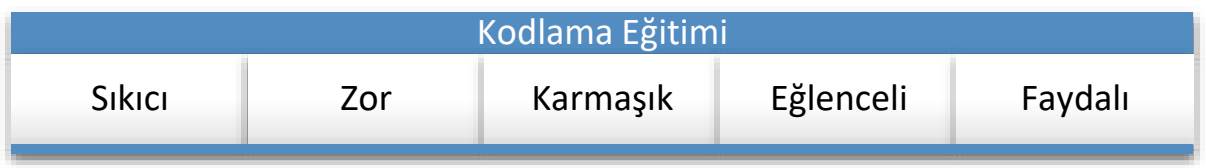

Şekil 2. Kodlama Eğitimi Temasına Yönelik Kodlar

Öğrencilerin kodlama eğitimine yönelik görüşleri incelendiğinde ise kodlamanın öğrencilere sağladığı yaratıcılık gibi birçok olanak nedeniyle çoğunluklu olumlu görüşlere yer almaktadır. Bir kısım öğrenciler ise kodlamanın zor veya karmaşık olduğunu düşünmelerine rağmen kodlama yaparken mutlu olduklarını, eğlendiklerini ifade etmişlerdir. Aynı zamanda kodlama eğitiminin katkısına ilişkin farkındalıklarının oldukça yüksek olduğu söylenebilir. Öğrencilerin ifadelerinden alıntılar şu şekildedir:

- «Neden sevmeyeyim ki? Sonuçta kendi oyununu yaratıyorsun, çok güzel bir şey..»

- «Biraz zor ama eğlenceli bir şey. Çünkü ilerde hasta olan bir insana el veya ayak yapabiliriz.»

- «Benimde hem bilişim hem de kodlama hoşuma gidiyor. Çünkü dikkatimi çekiyor, bazı yerlerde de zorlanınca mutlu oluyorum.»

- «Tabi ki bu dersi geleceğim için seviyorum. Gelecekte robotlar sayesinde bir yaşam süreceğiz ve bu robotlarda kodlama ile çalıştı̆̆ için hem bu benim geleceğim hem de arkadaşlarımın dünyanın geleceği olduğu için seviyorum.»

Öğrencilerin küçük bir kısmı ise kodlama eğitime yönelik olumsuz görüşlerini belirtmişlerdir. Olumsuz görüşlerin nedeni olarak zor, sıkıcı olması veya başarısız denemeler sonucunda kaygı veya korku oluşması gösterilmiştir. Öğrencilerin ifadelerinden alıntılar şu şekildedir:

- «Matematik, fen daha eğlenceli aslında. Ben sıkılıyorum bu derste.»

- «Sevmiyorum bu dersi. Aslında ilk başlarda zorlandım yapamadım sonra bir korku oluştu bende, ondan sevmiyorum.»

- «Sevmiyorum, aşırı karışık ve saçma geliyor.»

Öğrencilerin eşli kodlamaya yönelik görüşleri ise çoğunlukla olumlu yöndedir ve Şekil 3. te verilmiştir. 


\section{Eşli kodlama}

\begin{tabular}{|c|c|c|c|c|c|c|}
\hline $\begin{array}{c}\text { Hızlı } \\
\text { öğrenme }\end{array}$ & $\begin{array}{c}\text { Hızlı hata } \\
\text { ayıklama }\end{array}$ & $\begin{array}{c}\text { Sosyal } \\
\text { beceriler }\end{array}$ & Etkileşim & $\begin{array}{c}\text { Olumlu } \\
\text { Bağlılık }\end{array}$ & $\begin{array}{c}\text { Takım } \\
\text { çalışması }\end{array}$ & Dayanışma
\end{tabular} Çatışma

\section{Şekil 3. Eşli Kodlama Temasına Yönelik Kodlar}

Eşli kodlamada yönlendiren - kontrol eden görevlerinden hangisini almayı tercih ettikleri sorulduğunda ise benzer oranlara ulaşılmıştır. Kimi öğrenciler hata ayıklamanın daha kolay olduğu gerekçesiyle kontrol eden olmayı tercih ederken kimi öğrenci yönlendiren olmayı daha eğlenceli bulmaktadır. Öğrencilerin eşli kodlamaya yönelik görüşleri şu şekildedir:

- «Eşli çalışmaktan memnunum çünkü bir yerde ben takıldığımda diğer arkadaşım bana yardım edebiliyor. Onun takıldığı yerde benim bilgim varsa ben ona yardım edebiliyorum.»

- «Eşli kodlamadan memnunum, yaptığımın doğru olduğundan daha çok emin oluyorum.»

- «O başka bir şey istiyor, ben başka bir şey istiyorum, anlaşamıyoruz, ara sıra çatışıyoruz.»

- «Dersi dinlemediğinde öğretmen bunu mu dedi ne dedi diye sürekli soruyor. Sen yapacaksın nasıl olsa diyor.»

\section{Tartışma ve Sonuç}

İşbirlikli öğrenme, kodlama eğitimi ve eşli kodlamaya yönelik görüşlerin incelenmesinin amaçlandığı bu araştırmada, öğrencilerin kodlamaya yönelik tutumları ve eşli kodlamaya yönelik görüşlerinin olumlu olduğu sonucuna ulaşılmıştır. Literatür incelendiğinde ortaokul öğrencilerinin (Gürsoy ve Çekmez, 2019) veya farklı kademelerdeki öğrencilerin (Anastasiadou ve Karakos, 2011; Başer, 2013; Erol ve Kurt, 2017; Korkmaz ve Altun, 2013; Özyurt ve Özyurt, 2015) kodlamaya yönelik olumlu tutumlara sahip olduğu görülmektedir. Öğrencilerin kodlama eğitimine yönelik görüşleri farklılaşmaktadır. Öğrencilerin bir kısmı eğlenceli ve faydalı bulurken, diğer bir kısmı karmaşık ve sıkıcı bulmaktadır. Aynı zamanda kodlamayı zor olmasına rağmen sevdiğini ifade eden öğrencilerinde olduğu görülmektedir. Öğrencilerin kodlamaya yönelik olumsuz görüşlerini sıkıcı, karmaşık olmasının yanı sıra başarısızlık, 
kayg1, korku gibi nedenlere bağladıkları görülmüştür. Benzer şekilde Erol ve Kurt (2017) öğrencilerin sınav kaygısı, programlama korkusu, başarısızlık ve programlama mantığını anlayamama gibi nedenlerle olumsuz tutum sergilediklerini ortaya koymuştur.

Ortaokul seviyesindeki öğrencilerin, bilgisayar programlama sürecindeki teknik karmaşa içerisinde boğulmadan programlama mantı̆̆ını kavramasının, sonraki yıllarda öğrencilerin ilgilendikleri programlama dilleri ile çalı̧̧malarını kolaylaştıracağı düşünülmektedir. Önemli olan kodlama mantığ1nın öğrencilere öğretilmesidir; sonrasında öğrencilerin farklı kodlama dilleri geçişinde yalnızca yazımsal dil bilgisinin öğrenilmesi yeterli olacaktır.

İlkokul/ortaokul seviyesindeki öğrencilerin bilgisayar programlamayı öğrenmelerini destekleyecek çok sayıda internet sitesi ve yazilımlar bulunmaktadır. Code.org, Kodu Game ve Scratch gibi internet sitesi ve uygulamalar teknik bilgilerden arındırılmış, kullanılması kolay ve kodlama mantığını öğretmeye yönelik hazırlanmıştır. Görsel, blok tabanlı ve oyun tabanlı programlama dilleri ile yapılan çalışmalar yoğunlaşmakta ve bu çalışmalarda küçük yaşlarda kodlama eğitimi alan öğrencilerin eleştirel düşünme ve problem çözme becerilerinde artış, olduğu sonucuna ulaşılmıştır (Doğan ve Kert, 2016; Coşar, 2013). Geliştirilen Alice, Microsoft Small Basic, Scratch, Stagecast Creator ve Toontalk gibi programlamayı somutlaştıran ve öğrenmeyi kolaylaştıran ortamlar ile kodlama eğitimi öğrencilerin okuma yazma bilgisine ihtiyaç duymadan -okul öncesi dönemde- kodlama yapabilmesini sağlamaktadır. Bu ortamlar ile kodlamaya küçük yaşlarda başlayan öğrenciler için görsel programlama dilleri ile kodlama eğitimi oldukça kolay, anlaşılır ve eğlenceli olarak görülmektedir.

Cinsiyet açısından işbirlikli öğrenmeye yönelik tutum puanlarında anlamlı bir farklılık bulunmazken ve kodlamaya yönelik tutum puanlarında erkek öğrencilerin lehine anlamlı bir farklılık bulunmuştur. Araştırma sonuçları erkek öğrencilerin kodlamaya yönelik tutumların daha olumlu olduğunu gösteren araştırmalarla benzerlik göstermektedir (Başer, 2003; Korkmaz ve Altun, 2013, Özyurt ve Özyurt, 2015). Ancak kodlamaya yönelik tutum açsından cinsiyete göre bir farkın bulunmadığı araştırma sonuçları da bulunmaktadır (Erol ve Kurt, 2017; Gürsoy ve Çekmez, 2019; Kalelioğlu, 2015). Bu açıdan literatür incelendiğinde bu konuda bir uyuşma olmadığı görülmektedir. Kız öğrencilerin kodlama eğitiminde dezavantajı konumda olmamaları adına erken yaşta kodlama eğitiminin önemi vurgulanmaktadır. Bu şekilde 
öğrencilerin kodlamaya yönelik görüşlerin olumlu yönde gelişeceği ifade edilmektedir (Durak, Yılmaz, Yılmaz ve Seferoğlu, 2017).

Araştırmada, öğrencilerin işbirlikli öğrenmeye yönelik tutumlarının olumlu olduğu görülmüştür. Literatürde işbirlikli öğrenmenin faydalı, zevkli, yaratıcı olduğu yönünde olumlu öğrenci görüşleri bu durumu destekler niteliktedir (Doymuş, Şimşek ve Bayrakçeken, 2004; Ergün, 2006). İşbirlikli öğrenme, geleneksel öğretim yöntemlerine nazaran akademik başarıya katkısı daha fazla olan öğretim yöntemlerinden olmakla birlikte (Camnalbur ve Mutlu Bayraktar, 2018); öğrencilerin işbirlikli öğrenme yönteminin kullanıldığı derse yönelik tutumların da olumlu etkilemektedir (Gök, Doğan, Doymuş ve Karaçöp, 2009). İşbirlikli öğrenme yönteminin bilişim teknolojileri (Birişçi ve Karal, 2011) kodlama eğitimi (Yılmaz, 2019) araştırmalarında akademik başarıya olumlu etkisi görülmektedir. Bu açıdan işbirlikli öğrenmeye yönelik olumlu tutumların eşli kodlama uygulamalarını ve akademik başarıyı olumlu yönde etkileyeceği öngörülebilir. Zira araştırma kapsamında işbirlikli öğrenmeye yönelik tutum ile kodlamaya yönelik tutum arasında anlamlı bir ilişki saptanmıştır. Öğrencilerin eşli kodlamaya yönelik görüşleri de bu bulguları destekler niteliktedir. Eşli kodlama uygulaması açısından bakıldığında öğrenciler işbirlikli öğrenme bağlamında da çeşitli katkılarından söz etmişlerdir. Literatürde Scratch uygulamasında farklı işbirlikli öğrenme tekniklerinden olan birlikte öğrenme ve ayrılıp birleşme tekniklerinin kullanıldığı araştırmalarda, bu tekniklerin akademik başarıyı ve derse yönelik tutumları olumlu etkilediği sonuçlarına ulaşılmıştır (Yılmaz, 2019; Yüksel ve Gündoğdu, 2018).

Kodlama eğitimi sadece profesyonel programclar yetiştirmeyi değil aynı zamanda, 21. yy bireylerinin yaratıcı fikir geliştirme süreçlerini de desteklemeyi amaçlamaktadır. Öğrencilerin yaratıc bir şekilde içerik oluşturup paylaşmalarında uygun ortamlar sağladığı belirtilmektedir. Programlama mantığını öğrenen öğrencilerin kendilerini ifade etme ve iletişim geliştirme açısindan da uygun bir ortam yarattı̆g söylenebilmektedir. Bu bağlamda 21.yy becerileri olarak ifade edilen eleştirel düşünme, problem çözme, yaratıcllık, iletişim ve işbirliği, sosyal beceriler, üretkenlik, liderlik ve sorumluluk becerilerinin kazandırılmasında kodlama eğitiminin işlevsel olduğu düşünülmektedir (Durak, Yılmaz, Yılmaz ve Seferoğlu, 2017). 
Sonuç olarak öğrencilerin hem kodlama eğitimine hem işbirlikli öğrenmeye yönelik olumlu tutumlarından yola çıkılarak, kodlama eğitiminde işbirlikli öğrenme yaklaşımının bir örneği olan eşli kodlama, teknik altyapı yetersizliği dezavantajını avantaja çevirebilme açısından önemli bir firsat ve pedagojik bir altyapı sunmaktadır. Teknoloji entegrasyonunun önündeki en önemli engellerden biri olan teknik altyapı yetersizliği, gerekli pedagojik düzenlemeler ile ortadan kaldırılabilir. Bu sayede hem öğretmenlerin hem de öğrencilerin eğitimde teknoloji kullanımına yönelik tutum ve inançları geliştirilebilir. Bu araştırma kodlama eğitimi, işbirlikli öğrenme ve eşli kodlamaya yönelik görüşler belirlenmiştir. Yapılacak yeni araştırmalarla eşli kodlamanın akademik başarıya etkisi deneysel araştırmalarla test edilebilir. Eşli kodlama yöntemine ilişkin farklı kademelerdeki öğrencilerin görüşleri incelenebilir. 


\title{
EXTENDED ABSTRACT
}

\section{Collaborative Learning Approach in Coding Education: Pair Programming}

\author{
$*$ \\ Şule Betül Tosuntaş - Emrah Emirtekin - Kağan Kırcaburun \\ Bursa Uludağ University, Yaşar University, Düzce University
}

Coding education; besides providing coding knowledge and skills; it requires individuals to use high-level thinking skills, to think systematically, to look at problems from different perspectives and to produce solutions, to create cause-effect relation and to think creatively (Yükseltürk \& Altıo, 2015). In the world, coding education has gained importance in recent years with the emphasis on using technology not only as a means of consumption but as a means of production. Although individuals use information technologies continuously, they do not contribute to information technologies and this situation is expressed as "being able to read and but not being able to write" (Resnick et al., 2009).

It is added to primary and secondary school programs all over the world in order to develop cooperation, critical thinking, algorithmic thinking, creative thinking and problem solving which form the basis of information-processing. Many countries in a manner similar coding education in Turkey was included in the Information Technology and Software curriculum began to be taught to students from 6th grade. Coding education is provided using approaches such as computer-free activities, block-based programming, robotics programming, and game-based learning. Pair programming is one of the approaches that reflect cooperative learning on coding education. Theoretically, pair programming is known to have many advantages. The aim of this study is to examine the attitudes of secondary school students towards cooperative learning and coding and their views on pair programming practices.

Explanatory sequential pattern, in which quantitative and qualitative data were collected consecutive, was preferred in the study. Participants are 220 secondary school students determined by criterion sampling. In this context, participation in pair programming practices was evaluated as a criterion. The 
students who met the criteria filled Attitude towards Cooperative Learning Scale and Attitude towards Coding Scale. Cooperative Learning Scale developed by Şahin, Arseven, Ökmen, Eriş, and İlğan (2017) was used to determine the attitudes of students towards cooperative learning. Attitudes towards coding were collected using the Attitude towards Coding Scale developed within the scope of the research. The qualitative data of the research was collected through focus group interviews using a semi-structured interview form consisting of 6 questions.

As a result of the research, it was determined that students' attitudes towards cooperative learning and coding were positive. There is no significant difference between gender in terms of attitudes towards cooperative learning. However, there is a significant difference between gender in terms of attitudes towards coding. A positive correlation was determined between the attitude towards coding and cooperative learning. The students' views on coding education and paired coding through focus group interviews were examined under two themes. Under the theme of coding education, positive and negative opinions of the students are included. When students' views on coding education are examined, their views are mostly positive due to many opportunities such as creativity that coding provides students. When the literature is examined, it was found that middle school students (Gürsoy and Çekmez, 2019) or students of different levels (Anastasiadou \& Karakos, 2011; Başer, 2013; Erol \& Kurt, 2017; Korkmaz \& Altun, 2013; Özyurt \& Özyurt, 2015) have positive attitudes towards coding. Accordingly, the positive effects of cooperative learning were emphasized in the views on the application of pair programming. Cooperative learning method has a positive effect on academic success in information technologies (Birişçi \& Karal, 2011), and coding education (Yilmaz, 2019) research. In this context, new approaches used in the world in terms of coding education should be applied and disseminated. It is necessary to create sample modules related to practices and lesson plans that can be used in coding education and to share them with teachers. It is thought that the sample modules will guide teachers in creating their own coding training routines. Paired coding-like approaches, which are also an innovative technology-assisted cooperative learning approach, will serve as an important example for teachers and schools to overcome the lack of technical infrastructure in coding education. Because paired coding is one of the proposed approaches in order to turn technical infrastructure shortage into 
an advantage. In this context, it will be possible to make coding education with the limited technology available in schools. However, pre-service teachers feel deficient in methods and approaches to coding education. In this respect, teacher educators should also focus on teach coding. Providing fieldspecific approaches in teacher education will enable teachers to teach coding more perfectly, which has an important place in the future. Consequently, based on their positive attitudes towards both coding education and cooperative learning, pair programming provides an important opportunity and pedagogical infrastructure in terms of turning the technical infrastructure disadvantage into an advantage.

\section{Kaynakça / References}

Açıkgöz, K. Ü. (1992). İşbirlikli öğrenme: Kuram araştırma uygulama. Malatya: Uğurel Matbaası.

Albaaly, E. ve Higgins, S. (2012). The impact of interactive whiteboard technology on medical students' achievement in ESL essay writing: an early study in Egypt. The Language Learning Journal, 40(2), 207-222.

Anastasiadou, S. D. ve Karakos, A. S. (2011). The beliefs of electrical and computer engineering students' regarding computer programming. International Journal of Technology, Knowledge \& Society, 7(1), 37-51.

Anderson, J. C. ve Gerbing, D. (1984). The effect of sampling error on convergence, improper solutions, and goodness-of-fit indices for maximum likelihood confirmatory factor analysis. Psychometrika, 49, 155-173.

Arabacioglu, C., Builbuil, H., ve Filiz, A. (2007). Bilgisayar programlama ögretiminde yeni bir yaklaşım [A new approach to computer programming teaching]. Presented at Akademik Bilişim Konferansı [Academic Informatics Conference], January 31-February 2, Kütahya, Turkey.

Başer, M. (2013). Bilgisayar programlamaya karşı tutum ölçeği geliştirme çalışmasi. The Journal of Academic Social Science Studies, 6(6), 199-215.

Beck, K. ve Andres, C., (2004). Extreme programming explained: Embrace change (Second ed.). Boston: Addison-Wesley Professional.

Birişçi, S. ve Karal, H. (2011). Öğretmen adaylarının bilgisayar destekli ortamda materyal tasarlarken işbirlikli çalışmalarının yaratıcı düşünme becerilerine etkisi. Journal of Kirsehir Education Faculty, 12(2). 
Braun, V. ve Clarke, V. (2019). Psikolojide tematik analizin kullanımı. S. N. Şad*, N. Özer ve A. Atli (C,evirenler). Eğitimde Nitel Araştırmalar Dergisi - Journal of Qualitative Research in Education, 7(2), 873-898. doi: 10.14689/issn.2148-2624.1.7c.2s.17m

Camnalbur, M. ve Mutlu Bayraktar, D. (2018). İşbirlikli öğrenmenin akademik başarı üzerine etkisi: Bir meta-analiz çalışması. Itobiad: Journal of the Human \& Social Science Researches, 7(2).

Cockburn, A. ve Williams, L. (2000). The costs and benefits of pair programming. Extreme programming examined, 8, 223-247.

Code.org (2018). What is Code.org? 01.04.2018 tarihinde https://support.code.org/hc/en-us/articles/204784827-What-is-Code-org-. adresinden erişilmiştir.

Cole, D. A. (1987). Utility of confirmatory factor analysis in test validation research. Journal of Consulting and Clinical Psychology, 55(4), 1019-1031.

Coşar, M. (2013). Problem temelli öğrenme ortamında bilgisayar programlama çalı̧̧malarınn akademik başarı, eleştirel düşünme eğilimi ve bilgisayara yönelik tutuma etkileri. Yayınlanmamış doktora tezi. Gazi Üniversitesi, Ankara.

Creswell, J. W. (2002). Educational research: Planning, conducting, and evaluating quantitative and qualitative research (4th ed.). Boston: Pearson.

Demir, Ö. Ve Seferoğlu, S. S. (2018). İşbirlikli problem çözmenin kodlama öğretimine yansıması olarak eşli kodlamanın incelenmesi. In 5th International Instructional Technologies \& Teacher Education. İzmir, Turkey.

Demirel, Ö. (2008). Öğretim ilke ve yöntemleri: Öğretme sanatı.(13. Baskı) Ankara: Pegem Akademi.

Doğan, U. ve Kert, S. B. (2016). Bilgisayar oyunu geliştirme sürecinin, ortaokul öğrencilerinin eleştirel düşünme becerilerine ve algoritma başarılarına etkisi. Boğaziçi Üniversitesi Eğitim Dergisi, 33(2), 21-42.

Doymuş, K., Şimşek, Ü. ve Bayrakçeken, S. (2004). İşbirlikçi öğrenme yönteminin fen bilgisi dersinde akademik başarı ve tutuma etkisi. Journal of Turkish Science Education, 1(2), 103-115.

Durak, H., Karaoğlan-Yllmaz, G., Yılmaz, R. ve Seferoğlu, S. S. (2017). Erken yaşta programlama eğitimi: Araştırmalardaki güncel eğilimlerle ilgili bir inceleme. H. F. Odabaşı, B. Akkoyunlu ve A. İşman (Ed.), Eğitim teknolojileri okumaları (s. 205-236). Adapazarı: Tojet ve Sakarya Üniversitesi.

Erciyeş, G. (2007). Öğretim yöntem ve teknikleri. Ş. Tan. (Editör). Öğretim Illke ve Yöntemleri. (2.Baskı). Ankara: Pegem A Yayıncılık. 
Ergün, A. (2006). İşbirlikli öğrenme yönteminin ilköğretim sekizinci smmffen öğretimine etkileri. Yayımlanmamış yüksek lisans tezi. Pamukkale Üniversitesi Fen Bilimleri Enstitüsü, Denizli.

Erol, O. ve Kurt, A. A. (2017). BÖTE bölümü öğrencilerinin programlamaya karşı tutumlarını incelenmesi. Mehmet Akif Ersoy Üniversitesi Eğitim Fakültesi Dergisi, 1(41), 314-325.

Giordano, D. ve Maiorana, F. (2014, April). Use of cutting edge educational tools for an initial programming course. In Global Engineering Education Conference (EDUCON), 2014 IEEE (p. 556-563). IEEE.

Gök, Ö., Doğan, A., Doymuş, K. ve Karaçöp, A. (2009). İşbirlikli öğrenme yönteminin ilköğretim öğrencilerinin akademik başarılarına ve fene olan tutumlarına etkileri. Gazi Üniversitesi Gazi Eğitim Fakültesi Dergisi, 29(1), 193-209.

Günüç, S., Odabaşı, H.F. ve Kuzu, A., (2013). 21. Yüzyıl öğrenci özelliklerinin öğretmen adayları tarafindan tanımlanması: bir twitter uygulaması. Ĕgitimde Kuram ve Uygulama, 9(4), 436-455.

Gürsoy, K. ve Çekmez, E. (2019). Ortaokul öğrencilerinin programlamaya yönelik tutumlarınn ve görüşlerinin incelenmesi. Türk Bilgisayar ve Matematik Ĕ̈itimi Dergisi, 10(3), 757-777.

Jöreskog, K. ve Sörbom, D. (2001). LISREL 8.51. Mooresvile: Scientific Software.

Kafai, Y. (2007). From SuperGoo to Scratch: exploring creative digital media production in informal learning. Learning, Media and Technology, 2(32), 149166.

Kafai, Y., Resnick, M. ve MaLoney, J. (2009). Scratch: Programming for All. Communications of the Acm, 11(52), 60-67.

Kalelioğlu, F. (2015). A new way of teaching programming skills to K-12 students: Code. org. Computers in Human Behavior, 52, 200-210.

Kaucic, B. ve Asic, T., (2011). Improving introductory programming with Scratch? In Proceeding of the 34th MIPRO International Conference, p. 1095-1100, Opatija, Croatia.

Keçeci, G., Alan, B. ve Zengin, F. K. (2016). Eğitsel bilgisayar oyunları destekli kodlama öğrenimine yönelik tutum ölçeği: geçerlilik ve güvenirlik çalışması. Education Sciences, 11(4), 184-194.

Kobsiripat, W. (2015). Effects of the media to promote the scratch programming capabilities creativity of elementary school students. Procedia-Social and Behavioral Sciences, 174, 227-232. 
Korkmaz, O.ve Altun, H. (2013). Engineering and ceit student's attitude towards learning computer programming. The Journal of Academic Social Science Studies International Journal of Social Science, 6(2), 1169-1185.

Lui, K. M. ve Chan, K. C. (2003, May). When does a pair outperform two individuals?. In International Conference on Extreme Programming and Agile Processes in Software Engineering (p. 225-233). Springer, Berlin, Heidelberg.

M.E.B. Talim ve Terbiye Kurulu Başkanlığı (2017). Ortaöğretim kurumları bilişim teknolojileri ve yazllım dersi öğretim programı, http://ttkb.meb.gov.tr/program2.aspx/program2.aspx?islem=1\&kno=196 web adresinden 15 Nisan 2017 tarihinde indirilmiştir.

Malik, N. ve Shanwal, V. K. (2015). A comparative study of academic achievement of traditional classroom and smart classroom technology in relation to intelligence. Educational Quest, 6(1), 21.

Marsh, H. W., Balla, J. R. ve McDonald, R. P. (1988). Goodness-of-fit indexes in confirmatory factory analysis: The effects of sample size. Psychological Bulletin, 103(3), 391-410. doi: 10.1007/BF01102761.

Mayer, R. ve Bayman P. (1988). Using conceptual models to teach BASIC computer programming. Journal of Educational Psychology, 3(80), 291-298.

Neuman, L. W. (2007). Toplumsal araştırma yöntemleri: Nitel ve nicel yaklaşımlar (Çev. S. Özge,). İstanbul: Yayın odası.

Özyurt, Ö. ve Özyurt, H. (2015). Bilgisayar programcilığı öğrencilerinin programlamaya karşı tutum ve programlama öz-yeterliklerinin belirlenmesine yönelik bir çalışma. Eğitimde Kuram ve Uygulama, 11(1), 51-67.

Sünbül, A.M. (2011). Öğretim ilke ve yöntemleri. (5. Baskı). Konya: Eğitim Kitabevi.

Şahin, Ş., Arseven, Z., Ökmen, B., Eriş, H. M. ve İlğan, A. İşbirlikli öğrenmeye yönelik tutum ölçeği: Geçerlik ve güvenirlik çalışması. Kırıkkale Üniversitesi Sosyal Bilimler Dergisi, 7(1), 73-88.

Williams, L. ve Kessler, R. (2002). Pair programming illuminated. Boston: AddisonWesley Longman Publishing Co., Inc.

Yılmaz, Ş. (2019). Scratch programı öğretiminde birlikte öğrenme tekniği kullanımının öğrencilerin akademik başarısına ve öz yeterlik algısına etkisi. Yayımlanmamış yüksek lisans tezi. Afyon Kocatepe Üniversitesi, Afyon.

Yüksel, S. (2017). Scratch programı öğretiminde ayrllı birleşme tekniğgi kullanımının öğrencilerin derse yönelik tutumuna akademik başarısına ve kalıcilğga etkisi. Yayınlanmamış yüksek lisans tezi, Adnan Menderes Üniversitesi, Sosyal Bilimler Enstitüsü. 
Yüksel, S. ve Gündoğdu, K. (2018). Scratch öğretiminde ayrllıp birleşme tekniği kullanımının derse yönelik tutuma akademik başarıya ve kalıcılığa etkisi. Ege Ĕ̆itim Dergisi, 19(1), 245-261.

Yükseltürk, E. ve Altıok, S. (2015). Bilişim teknolojileri öğretmen adaylarının bilgisayar programlama öğretimine yönelik görüşleri. Amasya Üniversitesi Eğitim Fakültesi Dergisi, 4(1), 50-65.

\section{Kaynakça Bilgisi / Citation Information}

Tosuntaş, Ş. B., Emirtekin, E. ve Kırcaburun, K. (2020). Kodlama eğitiminde işbirlikli öğrenme yaklaşımı: Eşli kodlama. OPUS-Uluslararası Toplum Araştırmaları Dergisi, 16(27), 490-515. DOI: 10.26466/opus.680327 